\title{
Awareness of and reactions to health and environmental harms of red meat among parents in the United States
}

\author{
Anna H Grummon ${ }^{1,2, *}$, Dina Goodman ${ }^{3}$, Lindsay M Jaacks ${ }^{4}$, Lindsey Smith Taillie ${ }^{5,6}$, \\ Christina A Chauvenet ${ }^{7}$, Meg G Salvia ${ }^{8}$ and Eric B Rimm ${ }^{8,9}$
}

'Harvard Center for Population and Development Studies, Harvard TH Chan School of Public Health, Cambridge, MA, USA: ${ }^{2}$ Department of Population Medicine, Harvard Medical School and Harvard Pilgrim Health Care Institute, Boston, MA, USA: ${ }^{3}$ Department of Global Health, Harvard TH Chan School of Public Health, Boston, MA, USA: ${ }^{4} \mathrm{Global}$ Academy of Agriculture and Food Security, The University of Edinburgh, Edinburgh, UK: ${ }^{5}$ Department of Nutrition, University of North Carolina Gillings School of Global Public Health, Chapel Hill, NC, USA: ${ }^{6}$ Carolina Population Center, University of North Carolina at Chapel Hill, Chapel Hill, NC, USA: ${ }^{7}$ Arnold School of Public Health, University of South Carolina, Columbia, SC, USA: ${ }^{8}$ Department of Nutrition, Harvard TH Chan School of Public Health, Boston, MA, USA: ${ }^{9}$ Department of Epidemiology, Harvard TH Chan School of Public Health, Boston, MA, USA

Submitted 25 January 2021: Final revision received 3 July 2021: Accepted 26 July 2021: First published online 29 July 2021

\begin{abstract}
Objective: Evidence of the health and environmental harms of red meat is growing, yet little is known about which harms may be most impactful to include in meat reduction messages. This study examined which harms consumers are most aware of and which most discourage them from wanting to eat red meat.

Design: Within-subjects randomised experiment. Participants responded to questions about their awareness of, and perceived discouragement in response to, eight health and eight environmental harms of red meat presented in random order. Discouragement was assessed on a 1-to-5 Likert-type scale.

Setting: Online survey.

Participants: 544 US parents.

Results: A minority of participants reported awareness that red meat contributes to health harms (ranging from $8 \%$ awareness for prostate cancer to $28 \%$ for heart disease) or environmental harms (ranging from $13 \%$ for water shortages and deforestation to $22 \%$ for climate change). Among specific harms, heart disease elicited the most discouragement (mean $=2 \cdot 82$ out of 5$)$, followed by early death $($ mean $=2.79)$ and plants and animals going extinct $($ mean $=2.75)$, though most harms elicited similar discouragement (range of means, 2.60$2 \cdot 82$ ). In multivariable analyses, participants who were younger, identified as Black, identified as politically liberal, had higher general perceptions that red meat is bad for health and had higher usual red meat consumption reported being more discouraged from wanting to eat red meat in response to health and environmental harms (all $P<0.05$ ).

Conclusions: Messages about a variety of health and environmental harms of red meat could inform consumers and motivate reductions in red meat consumption.
\end{abstract}

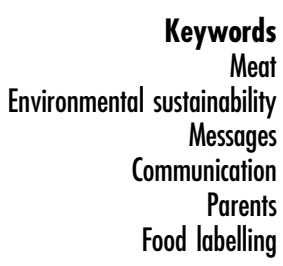

High consumption of meat, particularly red and processed meat, increases risk of CVD, diabetes and some cancers $^{(1-8)}$. Further, red meat is a major contributor to environmental harms such as greenhouse gas emissions ${ }^{(1,9-13)}$, air and water pollution ${ }^{(1,9)}$, biodiversity $\operatorname{loss}^{(1,14)}$ and deforestation $^{(14,15)}$. Reducing red meat consumption is therefore an important strategy for reducing chronic disease risk and mitigating environmental damage ${ }^{(16)}$.
Despite growing recognition of the health and environmental harms of red meat, American adults consume an average of $284 \mathrm{~g} /$ week (about 0.6 pounds) of unprocessed red meat alone (i.e. not including processed red meats such as bacon), nearly three times the maximum level recommended for optimising human and planetary health ${ }^{(2)}$. More than half of Americans say they are willing to eat less red meat ${ }^{(17)}$. Yet red meat consumption is projected to 
increase over the next decade ${ }^{(18)}$, perhaps in part because many Americans are unaware of the health and environmental harms of red meat ${ }^{(17,19)}$. Given this willingness to change, coupled with lack of awareness about red meat's impacts, educating consumers about the harms of red meat could reduce red meat consumption.

A growing body of research has shown that communicating about a products' health harms, for example, through product warning labels and mass media campaigns, is an effective strategy for reducing unhealthy behaviours including cigarette smoking ${ }^{(20,21)}$, alcohol consumption $^{(22)}$ and sugary drink consumption ${ }^{(22-25)}$. Similarly, a recent systematic review found that providing information about the health effects of meat consumption is an effective strategy for reducing intentions to eat meat as well as meat consumption ${ }^{(26)}$. Emerging literature also suggests the promise of communicating about products' environmental harms as a strategy for changing consumer behaviour. For example, a randomised experiment with undergraduate students in the UK found that sending students 2 weeks of daily messages about the environmental effects of meat production reduced students' red and processed meat consumption compared with a no-message control group $^{(27)}$. What remains unknown is which specific health and environmental harms hold the most promise for motivating consumers to reduce their red meat intake. Identifying the specific harms that most discourage red meat intake is important because messaging campaigns may not be able to communicate about all harms (e.g. due to space constraints), and because prior studies of tobacco and sugary drink messages suggest advantages to shorter, simpler messages ${ }^{(28-32)}$. Also unknown is whether consumers' reactions to health and environmental harms of red meat vary by demographic characteristics, information that could help to tailor messages to specific groups.

To inform communication efforts, we examined consumers' responses to health and environmental harms of red meat in an experiment with US parents of young children. Parents are a critical group to study in dietary communication interventions because their behaviours influence both their own health and the dietary habits of their children $^{(33)}$. Parents of young children (i.e. under age five) are especially important, given that dietary habits in early childhood affect diet and health later in childhood and into adolescence $^{(34,35)}$. Moreover, US parents are nearly $40 \%$ less likely than non-parents to have reduced their red meat intake compared with 3 years ago ${ }^{(19)}$, suggesting red meat reduction campaigns may be especially beneficial for this group. Thus, the specific objectives of this study were to examine which health and environmental harms of red meat parents are aware of and which are most likely to discourage red meat consumption. Additionally, to provide insight on populations that might respond more strongly to messages about red meat's harms, we examined demographic predictors of awareness of health and environmental harms and of the extent to which these harms discouraged participants from wanting to consume red meat.

\section{Methods}

Prior to data collection, we pre-registered the sample size, hypotheses and analysis plan (https://aspredicted.org/ q5e9b.pdf). The only deviations from this plan were that we corrected for multiple comparisons using Bonferroni's method rather than Tukey's method because Tukey's method cannot be applied to mixed models, and that we conducted two unplanned exploratory analyses, examining: (1) predictors of awareness of health and environmental harms and (2) predictors of harm-induced discouragement separately for health $v$. environmental harms.

\section{Participants}

In January 2020, we recruited a convenience sample of 544 US adults using the survey research firm Dynata as part of a study of parents' responses to experimental stimuli and survey questions. Participants were eligible if they were aged 18 years or older and had a child aged 6 months to 5 years. Online convenience samples can provide efficient and generalisable findings for experiments like the one used in this study ${ }^{(36)}$.

\section{Procedures}

Participants provided informed consent, completed an online survey programmed in Qualtrics and received incentives from Dynata (e.g. gift cards, reward points).

\section{Measures}

A flow of survey questions is shown in Fig. 1. First, participants answered questions about their usual red meat consumption $^{(19,37)}$ and general perceptions that red meat is bad for health and for the environment (e.g. 'How bad or good for your health do you think eating red meat is?'). Next, they responded to questions about their awareness of, and discouragement in response to, specific health and environmental harms of red meat. The order of presentation of health and environmental harms was randomised such that half of participants answered questions about health harms first and half answered questions about environmental harms first.

We assessed awareness of harms using a select-all-thatapply question adapted from previous studies ${ }^{(38-40)}$, 'Before today, had you ever heard that eating red meat can contribute to the following harms?' Then, we listed the eight health or eight environmental harms, displayed in random order. Participants could also select 'I haven't heard of red meat contributing to any of these harms before;' this option was always displayed last.

Next, we assessed the extent to which each harm discouraged participants from wanting to eat red meat using 


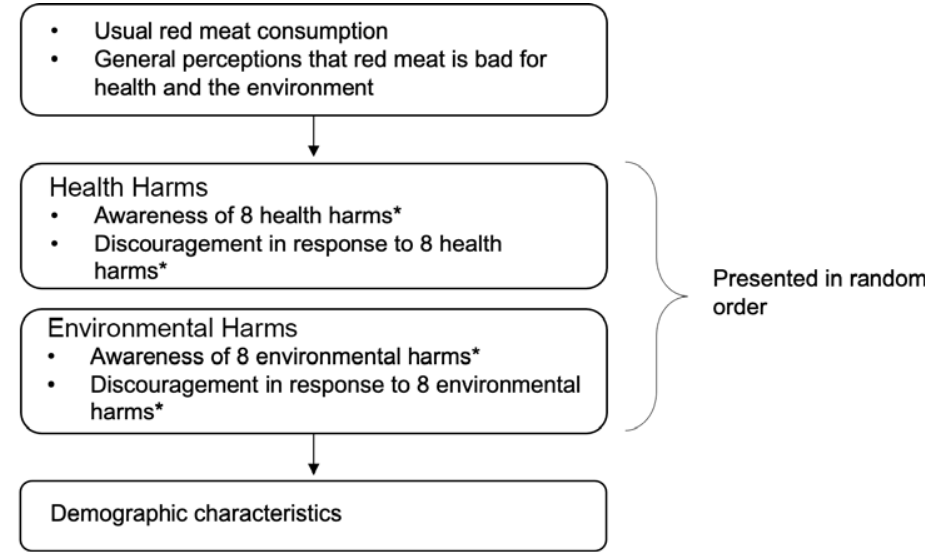

*The 8 specific harms in each block (health and environmental) were presented in random order. Harms are listed in Table 1.

Fig. 1 Flow chart of survey questions

an item adapted from previous studies ${ }^{(38-40)}$, 'How much does knowing that eating red meat contributes to these harms discourage you from wanting to eat red meat?' We assessed perceived discouragement because meta-analytic evidence indicates that perceived message effectiveness is predictive of actual message effectiveness ${ }^{(41)}$. Participants rated perceived discouragement in response to each harm on a 5-point scale, from 'Not at all' (coded as 1) to 'Very much' (coded as 5).

We selected harms to present based on recent literature linking red meat production and consumption with health and environmental harms (Table 1). The eight health harms were type 2 diabetes ${ }^{(42,43)}$, weight gain ${ }^{(43-45)}$, heart disease $\mathrm{e}^{(43,46)}$, stroke $\mathrm{e}^{(47,48)}$, colon cancer ${ }^{(43,49,50)}$, prostate cancer $^{(49)}$, stomach cancer ${ }^{(49)}$ and early death ${ }^{(43,51)}$. The eight environmental harms were climate change ${ }^{(14,15)}$, more greenhouse gases ${ }^{(1,9-12)}$, water shortages ${ }^{(1,11,52)}$, water pollution $^{(1)}$, air pollution ${ }^{(9)}$, plants and animals going extinct ${ }^{(1,14)}$, clearing of forests $^{(14,15)}$ and worse land quality ${ }^{(1,15,53)}$. All participants rated their awareness and discouragement for each of the eight health harms and each of the eight environmental harms. Within each type of harm (health $v$. environmental), specific harms were presented in random order.

Finally, the survey assessed standard demographics. Survey measures appear in online supplementary material, Supplemental Exhibit 1.

\section{Analysis}

First, we calculated the proportion of participants who reported they were aware of each harm and the mean discouragement ratings for each harm. We also calculated the proportion of participants who were aware of at least one harm, and the mean number of harms for which participants indicated awareness, both overall and separately for health and environmental harms. Next, we assessed whether likelihood of reporting awareness of harms was higher for health compared with environmental harms using mixed effects logistic regression, regressing awareness (coded as $0 / 1$ for each harm) on an indicator variable for whether the harm was a health or environmental harm. These models treated the intercept as random to account for repeated measures within participants.

To shed light on the populations who were most aware of red meat's harms, analyses also examined demographic predictors of the total number of harms for which participants indicated awareness (summed across all sixteen health and environment harms). These analyses used negative binomial regression with robust standard errors. We regressed the total number of harms for which participants indicated awareness on the following potential predictors: age, gender, race/ethnicity, educational attainment, income, political leaning and usual red meat consumption. We also used this approach to examine predictors of awareness separately for health harms $v$. environmental harms.

Next, analyses assessed whether health or environmental harms were more effective at discouraging participants from wanting to eat red meat. These analyses used a linear mixed model, regressing harm-induced discouragement ratings on an indicator variable for whether the harm was a health or environmental harm, treating the intercept as random. We then assessed the extent to which each specific harm elicited discouragement using a linear mixed model with indicator variables for each of the sixteen harms (excluding one as the referent), again treating the intercept as random. We used $z$-tests to conduct pairwise comparisons of predicted mean discouragement for each harm, applying Bonferroni's method to adjust for multiple comparisons. These comparisons allowed us to determine which of the harms (if any) were more discouraging than the others while adjusting for repeated measures within participants.

To examine which population groups reported more discouragement in response to health and environmental harms of red meat, we also examined demographic predictors of average discouragement from wanting to eat red 
Table 1 Health and environmental harms of red meat shown in experiment and supporting evidence

\begin{tabular}{|c|c|}
\hline Red meat harms & Supporting evidence \\
\hline \multicolumn{2}{|l|}{ Health harms } \\
\hline Type 2 diabetes & $\begin{array}{l}\text { - Meta-analyses have found that both unprocessed and processed red meat intake are associated with } \\
\text { increased risk of type } 2 \text { diabetes }{ }^{(3,72)}\end{array}$ \\
\hline Weight gain & $\begin{array}{l}\text { - A systematic review }{ }^{(45)} \text { and a meta-analysis }{ }^{(44)} \text { found that red and processed meat intake is associated } \\
\text { with weight gain and increased risk of overweight and obesity }\end{array}$ \\
\hline Heart disease & $\begin{array}{l}\text { - Meta-analyses have found that red meat intake is associated with CVD risk factors }{ }^{(46)} \text { and increased risk } \\
\text { of CHD and heart failure }\end{array}$ \\
\hline Stroke & - Meta-analyses have found that red meat intake is associated with increased risk of stroke $(47,73)$ \\
\hline Colon cancer & $\begin{array}{l}\text { - Meta-analyses have found that red and processed meat intake is associated with increased risk of } \\
\text { colorectal cancer }{ }^{(4,74,75)} \text {. Additionally, the International Agency for Research on Cancer (IARC) classifies } \\
\text { red meat as probably carcinogenic to humans }{ }^{(5)}\end{array}$ \\
\hline Prostate cancer & $\begin{array}{l}\text { - A meta-analysis found that red meat intake is associated with increased risk of prostate cancer }{ }^{(5)} \\
\text { - A pooled analysis of fifteen prospective cohorts found that red and processed meat intake is associated } \\
\text { with increased risk of advanced prostate cancer }{ }^{(76)}\end{array}$ \\
\hline Stomach cancer & $\begin{array}{l}\text { - A meta-analysis found that red meat intake is associated with increased risk of gastric (i.e. stomach) } \\
\text { cancer }^{(77)}\end{array}$ \\
\hline Early death & $\begin{array}{l}\text { - A meta-analysis found that red meat intake is associated with increased risk of all-cause mortality }{ }^{(78)} \\
\text { - A pooled analysis of two prospective cohorts found that red meat intake is associated with increased risk } \\
\text { of all-cause mortality }{ }^{(79)}\end{array}$ \\
\hline \multicolumn{2}{|r|}{ 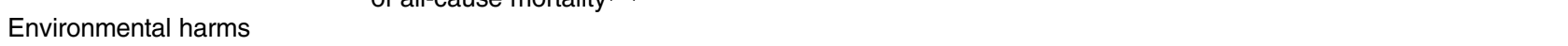 } \\
\hline Climate change & $\begin{array}{l}\text { - Systematic reviews of life cycle analyses indicate that production of red meat is a major contributor to } \\
\text { greenhouse gas emissions }^{(9,14)} \text {, which are a key driver of climate change }{ }^{(80)}\end{array}$ \\
\hline More greenhouse gases & $\begin{array}{l}\text { - Systematic reviews of life cycle analyses indicate that production of red meat is a major contributor to } \\
\text { - Ruminant (e.g. cowissions }{ }^{(9,14)} \\
\text { Roat, sheep) production is a major contributor to methane emissions }{ }^{(80,81)}\end{array}$ \\
\hline Water shortages & $\begin{array}{l}\text { - Production of red meat is a major contributor to water use }{ }^{(82)} \text { and water scarcity (i.e. the relative } \\
\text { freshwater availability in a given region) }\end{array}$ \\
\hline Water pollution & $\begin{array}{l}\text { Production of red meat is a major contributor to water pollution, including through leaching of fertilisers } \\
\text { and pesticides used to grow animal feed }{ }^{(82)} \text { and through increases in eutrophication }{ }^{(9)} \text { (the process by } \\
\text { which water becomes enriched with minerals and nutrients, stimulating algal blooms and other negative } \\
\text { ecological effects) }\end{array}$ \\
\hline Air pollution & $\begin{array}{l}\text { - Systematic reviews of life cycle analyses indicate that production of red meat is a major contributor to } \\
\text { acidifying emissions }\left(\text { e.g. } \mathrm{SO}_{2}, \mathrm{NH}_{3} \text { and } \mathrm{NO}_{x}\right)^{(9)}\end{array}$ \\
\hline $\begin{array}{l}\text { Plants and animals going } \\
\text { extinct }\end{array}$ & $\begin{array}{l}\text { - Meat production (particularly red meat) contributes to biodiversity loss through habitat destruction (e.g. } \\
\text { when land is converted to use for feed production or animal grazing, or due to nutrient pollution })^{(1,84,85)}\end{array}$ \\
\hline Clearing of forests & $\begin{array}{l}\text { - Red meat (particularly beef) production is a major contributor to deforestation (e.g. when forests are } \\
\text { converted to pasture for cattle) }\end{array}$ \\
\hline Worse land quality & - Red meat production contributes to land degradation via overgrazing, compaction and erosion ${ }^{(15,87)}$ \\
\hline
\end{tabular}

meat. First, we averaged discouragement ratings across all sixteen harms. We then used ordinary least squares linear regression to assess predictors of average discouragement. These analyses assessed the same demographic predictors as for awareness and additionally examined general perceptions that red meat is bad for health and for the environment. Exploratory analyses used the same approach to examine predictors of average harminduced discouragement separately for health harms $v$. environmental harms.

Analyses were conducted in 2021 using Stata MP version 16.1 (StataCorp LLC).

\section{Results}

Participants' average age was 33.8 (SD 8.0) years (range: 19-80). About two-thirds were White (69\%), $18 \%$ were Latino(a), $8 \%$ were another race/ethnicity and $5 \%$ were Black (Table 2). Slightly more than half (57\%) of participants identified as female and $22 \%$ had a high school education or less.
For each of the sixteen harms, fewer than one-third of participants indicated awareness that red meat contributed to that harm (Table 3). About one-third (33\%) of participants were not aware of any of the sixteen harms; $46 \%$ were not aware of any of the health harms, and $51 \%$ were not aware of any of the environmental harms. The specific harms with the highest level of awareness in the sample were heart disease ( $28 \%$ reported awareness), weight gain (27\%), climate change (22\%) and increased greenhouse gas emissions $(21 \%)$. Participants were least aware that red meat contributes to stomach cancer $(11 \%)$ and prostate cancer ( $8 \%)$. In mixed effects logistic regression, participants were similarly likely to report awareness of harms regardless of harm topic (health $v$. environment, $\mathrm{OR}=1.02$, $P=0.77)$.

In multivariate analyses examining predictors of the number of harms for which participants reported awareness, participants aged 26-34 years reported awareness of about 0.3 fewer harms of red meat compared with those aged $18-25$ years $(B=-0 \cdot 33, P=0.029$, Table 4$)$. Participants who identified as female reported being aware of fewer harms than those who identified as male $(B=-0 \cdot 26$, 
Table 2 Participant characteristics, n 544 US parents of young children

\begin{tabular}{|c|c|c|}
\hline Characteristic & $n$ & $\%$ \\
\hline \multicolumn{3}{|l|}{ Age in years } \\
\hline $18-25$ & 91 & 17 \\
\hline $26-34$ & 209 & 39 \\
\hline $35-44$ & 204 & 38 \\
\hline $45+$ & 38 & 7 \\
\hline \multicolumn{3}{|l|}{ Gender } \\
\hline Male & 227 & 42 \\
\hline Female & 308 & 57 \\
\hline Non-binary & 1 & 0.2 \\
\hline \multicolumn{3}{|l|}{ Race/ethnicity } \\
\hline Non-Hispanic White & 373 & 69 \\
\hline Non-Hispanic Black or African American & 29 & 5 \\
\hline Hispanic & 97 & 18 \\
\hline Non-Hispanic other & 45 & 8 \\
\hline \multicolumn{3}{|l|}{ Education } \\
\hline High school or less & 120 & 22 \\
\hline Some college & 85 & 16 \\
\hline College degree & 224 & 41 \\
\hline Graduate degree & 114 & 21 \\
\hline \multicolumn{3}{|l|}{ Annual household income } \\
\hline Less than $\$ 25000$ & 90 & 17 \\
\hline$\$ 25000-\$ 49999$ & 106 & 19 \\
\hline$\$ 50000-\$ 74999$ & 90 & 17 \\
\hline$\$ 75000-\$ 99999$ & 115 & 21 \\
\hline$\$ 100000$ or more & 143 & 26 \\
\hline \multicolumn{3}{|l|}{ Political party } \\
\hline Liberal & 136 & 25 \\
\hline Moderate & 218 & 40 \\
\hline Conservative & 189 & 35 \\
\hline \multicolumn{3}{|l|}{$\begin{array}{l}\text { General perceptions of how good or bad } \\
\text { red meat is for health }\end{array}$} \\
\hline Very bad & 29 & 5 \\
\hline Somewhat bad & 78 & 14 \\
\hline Neither good nor bad & 221 & 41 \\
\hline Somewhat good & 135 & 25 \\
\hline Very good & 80 & 15 \\
\hline \multicolumn{3}{|l|}{$\begin{array}{l}\text { General perceptions of how good or bad } \\
\text { red meat is to the environment }\end{array}$} \\
\hline Very bad & 29 & 5 \\
\hline Somewhat bad & 82 & 15 \\
\hline Neither good nor bad & 272 & 50 \\
\hline Somewhat good & 88 & 16 \\
\hline Very good & 73 & 13 \\
\hline \multicolumn{3}{|l|}{ Usual red meat intake (servings/d) } \\
\hline Mean & 0.7 & \\
\hline SD & 0.8 & \\
\hline
\end{tabular}

Missing data ranged from $0.0 \%$ to $1.5 \%$.

$P=0.023)$. Likewise, those who identified as politically moderate $(\mathrm{B}=-0.31, P=0.013)$ or conservative $(\mathrm{B}=-0.34$, $P=0.011)$ reported awareness of fewer harms than those who identified as liberal. Participants who identified as Black reported awareness of more harms than those identifying as White $(\mathrm{B}=0.57, P=0.006)$, but identifying as Latino(a) or as another race/ethnicity (compared with identifying as White) was not associated with awareness. Higher educational attainment and higher income were generally associated with being aware of more harms. Usual red meat consumption was not associated with being aware of more health and environmental harms of red meat $(\mathrm{B}=0.04, P=0.558)$.
Table 3 Awareness and discouragement of the health and environmental harms of red meat consumption, $n 544$ US parents of young children

\begin{tabular}{|c|c|c|c|}
\hline \multirow[b]{2}{*}{ Harm of red meat } & \multirow{2}{*}{$\frac{\text { Awareness }}{\%}$} & \multicolumn{2}{|c|}{$\begin{array}{c}\text { Discourage- } \\
\text { ment }\end{array}$} \\
\hline & & Mean & SD \\
\hline \multicolumn{4}{|l|}{ Health harms } \\
\hline Heart disease & 28 & $2 \cdot 82$ & 1.46 \\
\hline Weight gain & 27 & 2.75 & 1.45 \\
\hline Stroke & 17 & 2.75 & 1.45 \\
\hline Colon cancer & 14 & 2.74 & 1.46 \\
\hline Type 2 diabetes & 13 & 2.68 & 1.44 \\
\hline Early death & 13 & 2.79 & 1.49 \\
\hline Stomach cancer & 11 & $2 \cdot 72$ & 1.44 \\
\hline Prostate cancer & 8 & 2.60 & 1.47 \\
\hline \multicolumn{4}{|l|}{ Environmental harms } \\
\hline Climate change & 22 & $2 \cdot 70$ & 1.44 \\
\hline Greenhouse gas emissions & 21 & $2 \cdot 70$ & 1.44 \\
\hline Water pollution & 18 & $2 \cdot 69$ & 1.42 \\
\hline Air pollution & 16 & 2.67 & 1.42 \\
\hline Land quality & 16 & $2 \cdot 65$ & 1.42 \\
\hline Extinction of plants and animals & 14 & 2.75 & 1.45 \\
\hline Deforestation & 13 & $2 \cdot 68$ & 1.43 \\
\hline Water shortages & 13 & 2.68 & 1.45 \\
\hline
\end{tabular}

Table 4 Associations between participant characteristics and the total number of health and environmental harms of red meat for which participants reported awareness, $n 544$ US parents of young children

\begin{tabular}{|c|c|c|c|}
\hline & B & SE & $P$ \\
\hline \multicolumn{4}{|l|}{ Age in years } \\
\hline $18-25$ & Reference & & \\
\hline $26-34$ & -0.33 & 0.15 & 0.029 \\
\hline $35-44$ & -0.16 & 0.16 & 0.304 \\
\hline 45 or older & -0.03 & 0.21 & 0.886 \\
\hline Female* $^{*}$ & -0.26 & 0.11 & 0.023 \\
\hline \multicolumn{4}{|l|}{ Race/ethnicity } \\
\hline White & Reference & & \\
\hline Black & 0.57 & 0.21 & 0.006 \\
\hline Latino(a) & 0.07 & 0.14 & 0.622 \\
\hline Other race/ethnicity & 0.11 & 0.14 & 0.455 \\
\hline \multicolumn{4}{|l|}{ Education } \\
\hline High school or less & Reference & & \\
\hline Some college & 0.29 & 0.21 & 0.176 \\
\hline College degree & 0.51 & 0.18 & 0.003 \\
\hline Graduate degree & 0.52 & 0.21 & 0.013 \\
\hline \multicolumn{4}{|l|}{ Annual household income } \\
\hline Less than $\$ 25000$ & Reference & & \\
\hline$\$ 25000-\$ 49999$ & 0.37 & 0.20 & 0.062 \\
\hline$\$ 50000-\$ 74999$ & 0.42 & 0.19 & 0.028 \\
\hline$\$ 75000-\$ 99999$ & 0.40 & 0.20 & 0.045 \\
\hline$\$ 100000$ or more & 0.41 & 0.20 & 0.046 \\
\hline \multicolumn{4}{|l|}{ Political leaning } \\
\hline Liberal & Reference & & \\
\hline Moderate & -0.31 & 0.13 & 0.013 \\
\hline Conservative & -0.34 & 0.13 & 0.011 \\
\hline $\begin{array}{l}\text { Red meat consumption, } \\
\text { servings per day }\end{array}$ & 0.04 & 0.06 & 0.558 \\
\hline
\end{tabular}

Bs are unstandardised regression coefficients from negative binomial regressions, regressing the total number of health and environmental harms for which participants reported awareness on participant characteristics. Models estimated robust standard errors. Bold coefficients are statistically significant, $P<0.05$.

${ }^{\star}$ Referent group was male. The one non-binary participant was excluded from analysis due to small cell size. 
Fig. 2 (colour online) Health and environmental harms of red meat by discouragement and awareness, $n 544$ US parents of young children. 9 , health harms; $\Delta$, environmental harms

In analyses of awareness of health harms only, participants who identified as Black (compared with White) and those who had higher educational attainment reported awareness of a greater number of health harms. By contrast, participants who identified as politically moderate (compared with liberal) reported awareness of fewer harms (online supplementary material, Supplemental Table 1). In analyses of awareness of environmental harms only, being age 26-34 years (compared with 18-25), identifying as female (compared with male) and identifying as politically conservative (compared with liberal) were associated with awareness of fewer harms (online supplementary material, Supplemental Table 2). Higher education, higher income and higher usual red meat consumption were associated with awareness of more of the environmental harms of red meat.

In mixed effects regressions of harm-induced discouragement, health harms elicited slightly more discouragement than environmental harms, but the magnitude of the difference was small (mean discouragement $2.73 v$. 2.69 on the $1-5$ Likert scale; $\mathrm{B}=0.04, P=0.010$ ). Harms with higher awareness generally elicited higher discouragement (Fig. 2). Among specific harms, heart disease elicited the highest mean discouragement $($ mean $=2.82$ on the $1-5$ Likert scale), followed by early death (mean $=2 \cdot 79)$, plants and animals going extinct (mean $=2 \cdot 75)$, stroke $($ mean $=2.75)$ and weight gain $($ mean $=2.75)$ (Table 3$)$. Prostate cancer (mean $=2 \cdot 60)$ and worse land quality (mean $=2.65$ ) elicited the lowest discouragement. After adjusting for multiple comparisons, the only significant differences in discouragement between harms were that early death was more discouraging than prostate cancer (difference in predicted means $=0.20$, adjusted $P=0.002$ ), and heart disease was more discouraging than both prostate cancer (difference $=0.23$, adjusted $P<0.001$ ) and worsening land quality (difference $=0 \cdot 17$, adjusted $P=0.024$ ).

In multivariate analyses examining predictors of average discouragement ratings, older participants generally reported lower discouragement than younger participants (Table 5). Participants who identified as Black reported higher levels of average discouragement compared with White participants $(\mathrm{B}=0.56, P=0 \cdot 019)$. Those who identified as politically moderate $(\mathrm{B}=-0.40, P=0.002)$ or conservative $(\mathrm{B}=-0.64, P<0.001)$ were less discouraged by the health and environmental harms of red meat than those who identified as politically liberal. Participants who reported higher general perceptions that red meat is bad for health also reported higher average discouragement $(\mathrm{B}=0 \cdot 18, P=0 \cdot 006)$. By contrast, general perceptions that red meat is bad for the environment were not associated with average discouragement $(\mathrm{B}=0.07, P=0.329)$. Finally, participants who reported higher usual red meat consumption reported higher average discouragement $(\mathrm{B}=0.36, P<0.001)$. Gender, education, income and other race/ethnicities (i.e. Latino(a) and other race/ethnicity) were not associated with average discouragement (all PS $>0.05$ ). The pattern of results was similar when examining harm-induced discouragement separately for health $v$. environmental harms (online supplementary material, Supplemental Tables 3 and 4).

\section{Discussion}

Results of this study suggest that messages describing the health and environmental harms of red meat could be a 
Table 5 Associations between participant characteristics and average discouragement from wanting to eat red meat in response to health and environmental harms of red meat across, $n 544$ US parents of young children

\begin{tabular}{|c|c|c|c|}
\hline & B & SE & $P$ \\
\hline \multicolumn{4}{|l|}{ Age in years } \\
\hline $18-25$ & Reference & & \\
\hline $26-34$ & -0.40 & 0.16 & 0.011 \\
\hline $35-44$ & -0.41 & 0.16 & 0.013 \\
\hline 45 or older & -0.26 & 0.24 & 0.272 \\
\hline Female* $^{\star}$ & -0.04 & 0.12 & 0.724 \\
\hline \multicolumn{4}{|l|}{ Race/ethnicity } \\
\hline White & Reference & & \\
\hline Black & 0.56 & 0.24 & 0.019 \\
\hline Latino(a) & 0.22 & 0.14 & 0.119 \\
\hline Other race/ethnicity & -0.20 & 0.19 & 0.281 \\
\hline \multicolumn{4}{|l|}{ Education } \\
\hline High school or less & Reference & & \\
\hline Some college & 0.12 & 0.17 & 0.489 \\
\hline College degree & 0.29 & 0.16 & 0.063 \\
\hline Graduate degree & 0.32 & 0.20 & 0.109 \\
\hline \multicolumn{4}{|l|}{ Annual household income } \\
\hline Less than $\$ 25000$ & Reference & & \\
\hline$\$ 25000-\$ 49999$ & 0.09 & 0.18 & 0.607 \\
\hline$\$ 50000-\$ 74999$ & 0.07 & 0.19 & 0.702 \\
\hline$\$ 75000-\$ 99999$ & 0.32 & 0.20 & 0.113 \\
\hline$\$ 100000$ or more & 0.07 & 0.20 & 0.750 \\
\hline \multicolumn{4}{|l|}{ Political leaning } \\
\hline Liberal & Reference & & \\
\hline Moderate & -0.40 & 0.13 & 0.002 \\
\hline Conservative & -0.64 & 0.14 & $<0.001$ \\
\hline $\begin{array}{l}\text { General perceptions that red } \\
\text { meat is bad for health }\end{array}$ & 0.18 & 0.07 & 0.006 \\
\hline $\begin{array}{l}\text { General perceptions that red } \\
\text { meat is bad for the environment }\end{array}$ & 0.07 & 0.07 & 0.329 \\
\hline $\begin{array}{l}\text { Red meat consumption, servings } \\
\text { per day }\end{array}$ & 0.36 & 0.08 & $<0.001$ \\
\hline
\end{tabular}

Bs are unstandardised regression coefficients from ordinary least squares regressions regressing participants' average discouragement ratings (across all sixteen health and environmental harms) on participant characteristics. Bold coefficients are statistically significant, $P<0.05$.

${ }^{*}$ Referent group was male. The one non-binary participant was excluded from analysis due to small cell size.

promising strategy for discouraging red meat consumption among US parents of young children. The majority of respondents were not yet aware of the specific health and environmental harms of red meat assessed in this study, and one-third were not aware of any of the sixteen harms examined. These results suggest a major opportunity to educate consumers and motivate positive behaviour change. Expectancy disconfirmation theory posits that when consumers receive negative information about a product that conflicts with their prior expectations (e.g. being informed about the harms of red meat when they had previously not known these harms), their attitudes towards the product will become more negative ${ }^{(54-56)}$. This theory would suggest that correcting consumers' misperceptions about the health and environment risks of red meat could motivate them to reduce their red meat consumption. In line with this prediction, one study found that warning messages about the health harms of sugary drinks led to larger changes in parents' attitudes and purchase intentions when the messages were displayed on beverages parents had perceived as healthier compared with beverages parents already understood to be unhealthy ${ }^{(57)}$.

Regression analyses revealed that participants who were 26-34 years old (compared with 18-25 years), identified as female (compared with male) and identified as politically moderate or conservative (compared with liberal) reported awareness of fewer harms of red meat. By contrast, participants who identified as Black (compared with White) and those with higher educational attainment and higher income reported being aware of more harms. These results suggest that it may be beneficial to tailor awareness-raising campaigns to particular groups with lower awareness, such as parents who identify as female, are politically moderate or conservative or have lower educational attainment or income. However, given that the majority of participants were unaware that red meat contributes to the health and environmental harms assessed in this study, educational efforts are likely to benefit parents from all demographic groups.

Participants' usual red meat consumption was not related to their awareness of red meat's health harms, but higher red meat consumption did predict higher awareness of the environmental harms of red meat. The reason for this association is unclear. One explanation is that higher red meat consumers are more likely to pay attention to information about the environmental consequences of red meat consumption because this information is particularly relevant to them, but have not yet acted on their awareness by reducing their red meat consumption. Regardless of the explanation, this finding highlights that interventions would likely benefit from incorporating a variety of strategies to reduce red meat consumption, including increasing the accessibility, availability and attractiveness of non-meat options ${ }^{(58)}$.

Several participant characteristics predicted higher discouragement from wanting to eat red meat in response to health and environmental harms. For example, consumers aged 18-25 years reported higher discouragement in response to environmental harms of red meat compared with those aged 26-34 and 35-44 years, perhaps because young adults have stronger interest in environmental sustainability and greater concern about climate change than older adults ${ }^{(59-61)}$. Younger adults also reported higher discouragement in response to health harms than older adults. This pattern of results differs somewhat from prior research finding that younger adults were less likely than older adults to report health reasons for not eating meat ${ }^{(62)}$. Our results could potentially reflect a growing openness among young adults towards reducing their red meat consumption or consuming a plant-forward diet ${ }^{(63)}$, regardless of the precise motivation for making dietary changes. Participants who reported higher red meat consumption also reported higher discouragement in response to health and environmental harms of red meat. This finding is encouraging, as it suggests that messages about the harms of red meat might have the greatest impact on those who 
stand to benefit the most from reducing their red meat intake. Additionally, participants who had stronger general perceptions that red meat is bad for health reported being more discouraged, on average, in response the specific health and environmental harms examined in this study. By contrast, general perceptions that red meat is bad for the environment were not associated with average discouragement ratings. These findings might suggest that strengthening the public's general perception that red meat is bad for health could increase the public's receptivity to messages about specific health or environmental harms. However, the observed associations between participants' characteristics and their average discouragement ratings should be interpreted with caution because we cannot rule out the possibility that some demographic groups (such as young adults or those who hold stronger general perceptions that red meat is bad for health) might respond more strongly to any type of message presented in an online survey, even messages not about red meat. Studies that experimentally compare red meat messages to control messages are needed to establish whether characteristics like age, meat consumption, and general perceptions about red meat influence the effectiveness of red meat reduction messages on consumer behaviour.

Communication interventions such as product warnings and mass media campaigns that describe the health harms of cigarettes $^{(20,21)}$, alcohol ${ }^{(22)}$ and sugary drinks ${ }^{(22-25)}$ have been shown to generate small but meaningful reductions in purchases and consumption of these products, suggesting that communicating about the harms of red meat could help curb red meat intake. We found that both health and environmental harms elicited similar levels of perceived discouragement. Likewise, a variety of health and environmental harms were similarly discouraging to consumers. These results suggest that message developers have many promising options for topics to address in meat reduction messages. The limited differences in mean discouragement observed between the specific harms also suggest that communication campaigns could easily rotate among these harms, a strategy that could help prevent messages from becoming 'stale' and losing efficacy over time ${ }^{(64)}$.

The strengths of this study include the comprehensive set of health and environmental harms tested and the experimental comparison of how much each harm motivated participants to reduce their red meat consumption. Limitations include the use of a convenience sample of parents and the relatively young age distribution of the sample. Although prior studies indicate that online convenience samples can provide similar experimental results as probability samples ${ }^{(36,65,66)}$, future research should confirm our findings with non-parents and with a wider range of ages. Additionally, although we did not query whether participants were vegetarian or vegan, about $13 \%$ of our sample reported eating red meat less than 1 time per week during the past $30 \mathrm{~d}$. Future studies may wish to examine awareness and discouragement specifically among nonvegans/vegetarians or among high red meat consumers, for whom messages may be most relevant. Another limitation is that we did not assess whether some consumers believe that red meat is beneficial for specific health and environmental outcomes; understanding whether these beliefs are widespread, and who is most likely to hold these beliefs, could help inform messaging campaigns. Additionally, this study focused on health and environmental harms because these are two of the key reasons that US adults report as motivating them to change their diet or reduce their meat consumption ${ }^{(19,67)}$. However, consumers might also be motivated by other harms of red meat production. For example, a recent meta-analysis suggested that interventions appealing to animal welfare (e.g. by portraying farm animals) hold promise for reducing meat purchases and consumption ${ }^{(68)}$. We also did not assess other potentially important aspects of message design, such as message framing ${ }^{(69-71)}$. Finally, while perceived message effectiveness is predictive of behaviour change ${ }^{(41)}$, we did not assess behavioural outcomes. Future studies should experimentally evaluate the extent to which messages describing different types of harms of red meat reduce red meat purchases and consumption.

\section{Conclusions}

Reducing meat consumption is critical for mitigating climate change and reducing chronic disease burden ${ }^{(16)}$. Our study suggests that communication interventions describing how red meat consumption affects both human and planetary health hold promise for informing US consumers and motivating reductions in red meat consumption.

\section{Acknowledgements}

Acknowledgements: The authors thank Marissa G. Hall for helpful feedback on survey measures. Financial support: This research was funded in whole, or in part, by the Wellcome Trust (216042/Z/19/Z). For the purpose of open access, the author has applied a CC BY public copyright licence to any Author Accepted Manuscript version arising from this submission. DG was supported by T32 HL 098048. MGS was supported by T32 DK 007703. Conflict of interest: There are no conflicts of interest. Authorship: A.H.G., L.M.J., C.A.C. and L.S.T. designed and conceptualised the study. A.H.G., D.G. and M.G.S. contributed to data curation. A.H.G. and D.G. analysed the data and created data visualisations. A.H.G. drafted the initial manuscript. E.B.R. provided study oversight. All authors provided critical feedback on the manuscript draft and approved the final manuscript. Ethics of human subject participation: This study was conducted according to the guidelines laid down in the Declaration of Helsinki and all procedures involving 
research study participants were approved by the Harvard Longwood Campus Institutional Review Board. Written informed consent was obtained from all subjects/patients.

\section{Supplementary material}

For supplementary material accompanying this paper visit https://doi.org/10.1017/S1368980021003098

\section{References}

1. Clark MA, Springmann M, Hill J et al. (2019) Multiple health and environmental impacts of foods. Proc Natl Acad Sci USA 116, 23357.

2. Willett W, Rockström J, Loken B et al. (2019) Food in the Anthropocene: the EAT-Lancet Commission on healthy diets from sustainable food systems. Lancet 393, 447-492.

3. Pan A, Sun Q, Bernstein AM et al. (2011) Red meat consumption and risk of type 2 diabetes: 3 cohorts of US adults and an updated meta-analysis. Am J Clin Nutr 94, 1088-1096.

4. Vieira A, Abar L, Chan D et al. (2017) Foods and beverages and colorectal cancer risk: a systematic review and metaanalysis of cohort studies, an update of the evidence of the WCRF-AICR Continuous Update Project. Ann Oncol 28, $1788-1802$.

5. Bouvard V, Loomis D, Guyton KZ et al. (2015) Carcinogenicity of consumption of red and processed meat. Lancet Oncol 16, 1599-1600.

6. Bernstein A, Sun Q, Hu F et al. (2010) Major dietary protein sources and risk of coronary heart disease in women. Circulation 122, 876-883.

7. Springmann M, Godfray HCJ, Rayner M et al. (2016) Analysis and valuation of the health and climate change cobenefits of dietary change. Proc Natl Acad Sci 113, 4146-4151.

8. Al-Shaar L, Satija A, Wang DD et al. (2020) Red meat intake and risk of coronary heart disease among US men: prospective cohort study. BMJ 371, m4141.

9. Poore J \& Nemecek T (2018) Reducing food's environmental impacts through producers and consumers. Science $\mathbf{3 6 0}$, 987-992.

10. Heller MC, Willits-Smith A, Meyer R et al. (2018) Greenhouse gas emissions and energy use associated with production of individual self-selected US diets. Environ Res Lett 13, 044004.

11. Aleksandrowicz L, Green R, Joy EJ et al. (2016) The impacts of dietary change on greenhouse gas emissions, land use, water use, and health: a systematic review. PLoS One 11, e0165797.

12. Willits-Smith A, Aranda R, Heller MC et al. (2020) Addressing the carbon footprint, healthfulness, and costs of self-selected diets in the USA: a population-based cross-sectional study. Lancet Planet Health $\mathbf{4}$, e98-e106.

13. Boehm R, Ver Ploeg M, Wilde PE et al. (2019) Greenhouse gas emissions, total food spending and diet quality by share of household food spending on red meat: results from a nationally representative sample of US households. Public Health Nutr 22, 1794-1806.

14. Gerber PJ, Steinfeld H, Henderson B et al. (2013) Tackling Climate Change Through Livestock: A Global Assessment of Emissions and Mitigation Opportunities. Rome, Italy: Food and Agriculture Organization of the United Nations (FAO).

15. IPCC (2020) Summary for Policymakers. Climate Change and Land: An IPCC Special Report on Climate Change, Desertification, Land Degradation, Sustainable Land Management, Food Security, and Greenhouse Gas
Fluxes in Terrestrial Ecosystems. Geneva, Switzerland: IPCC.

16. Tilman D \& Clark M (2014) Global diets link environmental sustainability and human health. Nature 515, 518-522.

17. Leiserowitz A, Ballew M, Rosenthal S et al. (2020) Climate Change and the American Diet. New Haven, CT: Yale University and Earth Day Network.

18. Bentley J (2019) US Per Capita Availability of Red Meat, Poultry, and Seafood on the Rise. United States Department of Agriculture Amber Waves. https://www.ers.usda.gov/ amber-waves/2019/december/us-per-capita-availabilityof-red-meat-poultry-and-seafood-on-the-rise/ (accessed September 2020).

19. Neff RA, Edwards D, Palmer A et al. (2018) Reducing meat consumption in the USA: a nationally representative survey of attitudes and behaviours. Public Health Nutr 21, $1835-1844$

20. Noar S, Hall M, Francis D et al. (2015) Pictorial cigarette pack warnings: a meta-analysis of experimental studies. Tob Control 25, 341-354.

21. Brewer NT, Hall MG, Noar SM et al. (2016) Effect of pictorial cigarette pack warnings on changes in smoking behavior: a randomized clinical trial. JAMA Intern Med 176, 905-912.

22. Clarke N, Pechey E, Kosite D et al. (2020) Impact of health warning labels on selection and consumption of food and alcohol products: systematic review with meta-analysis. Health Psychol Rev 1-24. doi: 10.1080/17437199.2020. 1780147.

23. Grummon AH \& Hall MG (2020) Sugary drink warnings: a meta-analysis of experimental studies. PLoS Med 17, e1003120.

24. An R, Liu J, Liu R et al. (2020) Impact of sugar-sweetened beverage warning labels on consumer behaviors: a systematic review and meta-analysis. Am J Prev Med 60, $115-126$.

25. Schwartz MB, Schneider GE, Choi Y-Y et al. (2017) Association of a community campaign for better beverage choices with beverage purchases from supermarkets. JAMA Intern Med 177, 666-674.

26. Harguess JM, Crespo NC \& Hong MY (2020) Strategies to reduce meat consumption: a systematic literature review of experimental studies. Appetite 144, 104478.

27. Wolstenholme E, Poortinga W \& Whitmarsh L (2020) Two birds, one stone: the effectiveness of health and environmental messages to reduce meat consumption and encourage pro-environmental behavioral spillover. Front Psychol 11, 2596.

28. Noar SM, Kelley DE, Boynton MH et al. (2018) Identifying principles for effective messages about chemicals in cigarette smoke. Prev Med 106, 31-37.

29. Brewer NT, Jeong M, Hall MG et al. (2019) Impact of e-cigarette health warnings on motivation to vape and smoke. Tob Control 28, e64-e70.

30. Baig SA, Byron MJ, Boynton MH et al. (2017) Communicating about cigarette smoke constituents: an experimental comparison of two messaging strategies. J Behav Med 40, 352-359.

31. Grummon AH, Hall MG, Taillie LS et al. (2019) How should sugar-sweetened beverage health warnings be designed? A randomized experiment. Prev Med 121, 158-166.

32. Grummon AH, Hall MG, Mitchell CG et al. (2020) Reactions to messages about smoking, vaping and COVID-19: two national experiments. Tob Control 1-9. doi: 10.1136/ tobaccocontrol-2020-055956.

33. Savage JS, Fisher JO \& Birch LL (2007) Parental influence on eating behavior: conception to adolescence. J Law Med Ethics 35, 22-34.

34. Nicklaus S \& Remy E (2013) Early origins of overeating: tracking between early food habits and later eating patterns. Curr Obes Rep 2, 179-184. 
35. Singh AS, Mulder C, Twisk JW et al. (2008) Tracking of childhood overweight into adulthood: a systematic review of the literature. Obes Rev 9, 474-488.

36. Jeong M, Zhang D, Morgan J et al. (2018) Similarities and differences in tobacco control research findings from convenience and probability samples. Ann Behav Med 53, 476-485.

37. Thompson FE, Midthune D, Kahle L et al. (2017) Development and evaluation of the National cancer Institute's dietary screener questionnaire scoring algorithms. J Nutr 147, 1226-1233.

38. Rohde JA, Noar SM, Mendel JR et al. (2019) E-Cigarette health harm awareness and discouragement: implications for health communication. Nicotine Tob Res 22, 1131-1138.

39. Kelley DE, Boynton MH, Noar SM et al. (2018) Effective message elements for disclosures about chemicals in cigarette smoke. Nicotine Tob Res 20, 1047-1054.

40. Carl A, Taillie L, Grummon AH et al. (2021) Awareness of and reactions to the health harms of sugary drinks: an online study of US parents. Appetite 164, 105234.

41. Noar SM, Barker J, Bell T et al. (2018) Does perceived message effectiveness predict the actual effectiveness of tobacco education messages? A systematic review and meta-analysis. Health Commun 35, 148-157.

42. Feskens EJ, Sluik D \& van Woudenbergh GJ (2013) Meat consumption, diabetes, and its complications. Curr Diabetes Rep 13, 298-306.

43. Dietary Guidelines Advisory Committee (2020) Scientific Report of the 2020 Dietary Guidelines Advisory Committee: Advisory report to the Secretary of Agriculture and the Secretary of Health and Human Services. Washington, DC: United States Department of Agriculture, Agricultural Research Service.

44. Rouhani MH, Salehi-Abargouei A, Surkan PJ et al. (2014) Is there a relationship between red or processed meat intake and obesity? A systematic review and meta-analysis of observational studies. Obes Rev 15, 740-748.

45. Schlesinger S, Neuenschwander M, Schwedhelm C et al. (2019) Food groups and risk of overweight, obesity, and weight gain: a systematic review and dose-response metaanalysis of prospective studies. Adv Nutr 10, 205-218.

46. Guasch-Ferré M, Satija A, Blondin SA et al. (2019) Metaanalysis of randomized controlled trials of red meat consumption in comparison with various comparison diets on cardiovascular risk factors. Circulation 139, 1828-1845.

47. Kim K, Hyeon J, Lee SA et al. (2017) Role of total, red, processed, and white meat consumption in stroke incidence and mortality: a systematic review and meta-analysis of prospective cohort studies. J Am Heart Assoc 6, e005983.

48. Bernstein Adam M., Pan An, Rexrode Kathryn M et al. (2012) Dietary protein sources and the risk of stroke in men and women. Stroke 43, 637-644.

49. IARC Working Group on the Evaluation of Carcinogenic Risks to Humans (2018) Red Meat and Processed Meat. Lyon, France: International Agency for Research on Cancer.

50. World Cancer Research Fund/American Institute for Cancer Research (2018) Meat, Fish and Dairy Products and the Risk of Cancer. London: World Cancer Research Fund/American Institute for Cancer Research.

51. Etemadi A, Sinha R, Ward MH et al. (2017) Mortality from different causes associated with meat, heme iron, nitrates, and nitrites in the NIH-AARP Diet and Health Study: population based cohort study. BMJ 357, j1957.

52. Mekonnen MM \& Hoekstra AY (2011) The Green, Blue and Grey Water Footprint of Farm Animals and Animal Products. Delft, The Netherlands: UNESCO-IHE Institute for Water Education.

53. Foley JA, Ramankutty N, Brauman KA et al. (2011) Solutions for a cultivated planet. Nature $\mathbf{4 7 8}, 337-342$.
54. Van Raaij WF (1991) The Formation and Use of Expectations in Consumer Decision Making. Handbook of Consumer Behavior. Englewood Cliffs, NJ: Prentice Hall.

55. Burton S, Creyer E, Kees J et al. (2006) Attacking the obesity epidemic: the potential health benefits of providing nutrition information in restaurants. Am J Pub Health 96, $1669-1675$.

56. Burton S, Howlett E \& Tangari AH (2009) Food for thought: how will the nutrition labeling of quick service restaurant menu items influence consumers' product evaluations, purchase intentions, and choices? J Retailing 85, 258-273.

57. Moran AJ \& Roberto CA (2018) Health warning labels correct parents' misperceptions about sugary drink options. Am J Prev Med 55, e19-e27.

58. Ruby MB (2012) Vegetarianism. A blossoming field of study. Appetite 58, 141-150.

59. Saad L \& Jones JM (2016) US concern about global warming at eight-year high. Gallup Politics, March 16, 2016.

60. First Insight (2020) The State of Consumer Spending: Gen Z Shoppers Demand Sustainability Retail. Warrendale, PA: First Insight, Inc.

61. Washington Post and Kaiser Family Foundation (2019) Washington Post-Kaiser Family Foundation Climate Change Survey, July 9-Aug. 5, 2019. The Washington Post. https:// www.washingtonpost.com/context/washington-post-kaiserfamily-foundation-climate-change-survey-july-9-aug-5-2019/ 601ed8ff-a7c6-4839-b57e-3f5eaa8ed09f/?itid=lk_inline_ manual_4 (accessed May 2020).

62. Pribis P, Pencak RC \& Grajales T (2010) Beliefs and attitudes toward vegetarian lifestyle across generations. Nutrients $\mathbf{2}$, 523-531.

63. Pew Research Center (2016) Public Views about Americans' Eating Habits. Pew Research Center. https://www. pewresearch.org/science/2016/12/01/public-views-aboutamericans-eating-habits/ (accessed August 2021).

64. Hammond D (2011) Health warning messages on tobacco products: a review. Tob Control 20, 327-337.

65. Berinsky AJ, Huber GA \& Lenz GS (2012) Evaluating online labor markets for experimental research: amazon.com's Mechanical Turk. Political Anal 20, 351-368.

66. Weinberg JD, Freese J \& McElhattan D (2014) Comparing data characteristics and results of an online factorial survey between a population-based and a crowdsource-recruited sample. Sociol Sci 1, 292-310.

67. YouGov (2020) YouGov: Preferred Diets, Fieldwork dates 3rd-6th January, 2020. YouGov. https://docs.google.com/ viewer?url=https $\% 3 \mathrm{~A} \% 2 \mathrm{~F} \% 2 \mathrm{Fd} 25 \mathrm{~d} 2506 \mathrm{sfb} 94$ s.cloudfront.net \%2Fcumulus_uploads\%2Fdocument\%2Fuu7yxivmb6\%2F Results\%2520for $\% 2520$ YouGov\%2520RealTime\%2520(Preferred \%2520Diets)\%25202\%25201.6\%2520(version\%25201).xlsb\%25 20\%2520\%5BGroup\%5D\%5BAutoRecovered\%5D.pdf (accessed August 2021).

68. Mathur MB, Peacock J, Reichling DB et al. (2021) Interventions to reduce meat consumption by appealing to animal welfare: meta-analysis and evidence-based recommendations. Appetite 164, 105277.

69. Stea S \& Pickering GJ (2019) Optimizing messaging to reduce red meat consumption. Environ Commun 13, 633-648.

70. Duchene TN \& Jackson LM (2019) Effects of motivation framing and content domain on intentions to eat plantand animal-based foods. Soc Anim 27, 526-543.

71. Bertolotti M, Chirchiglia G \& Catellani P (2016) Promoting change in meat consumption among the elderly: factual and prefactual framing of health and well-being. Appetite 106, 37-47.

72. Schwingshackl L, Hoffmann G, Lampousi A-M et al. (2017) Food groups and risk of type 2 diabetes mellitus: a systematic 
review and meta-analysis of prospective studies. Eur $J$ Epidemiol 32, 363-375.

73. Bechthold A, Boeing H, Schwedhelm C et al. (2019) Food groups and risk of coronary heart disease, stroke and heart failure: a systematic review and dose-response metaanalysis of prospective studies. Crit Rev Food Sci Nutr 59, 1071-1090.

74. Zhao Z, Feng Q, Yin Z et al. (2017) Red and processed meat consumption and colorectal cancer risk: a systematic review and meta-analysis. Oncotarget 8, 83306.

75. Chan DSM, Lau R, Aune D et al. (2011) Red and processed meat and colorectal cancer incidence: meta-analysis of prospective studies. PLoS One 6, e20456.

76. Wu K, Spiegelman D, Hou T et al. (2016) Associations between unprocessed red and processed meat, poultry, seafood and egg intake and the risk of prostate cancer: a pooled analysis of 15 prospective cohort studies. Int J Cancer $\mathbf{1 3 8}$ 2368-2382.

77. Kim SR, Kim K, Lee SA et al. (2019) Effect of red, processed, and white meat consumption on the risk of gastric cancer: an overall and dose-response meta-analysis. Nutrients 11, 826.

78. Schwingshackl L, Schwedhelm C, Hoffmann G et al. (2017) Food groups and risk of all-cause mortality: a systematic review and meta-analysis of prospective studies. Am J Clin Nutr 105, 1462-1473.

79. Zheng Y, Li Y, Satija A et al. (2019) Association of changes in red meat consumption with total and cause specific mortality among US women and men: two prospective cohort studies. BMJ 365, 12110.
80. Edenhofer O, Pichs-Madruga R, Sokona Y et al. (2014) IPCC, 2014: Summary for Policymakers. Climate Change 2014: Mitigation of Climate Change. Contribution of Working Group III to the Fifth Assessment Report of the Intergovernmental Panel on Climate Change. Cambridge: Cambridge University Press.

81. Stocker T (2014) Climate Change 2013: The Physical Science Basis: Working Group I Contribution to the Fifth Assessment Report of the Intergovernmental Panel on Climate Change. Cambridge: Cambridge University Press.

82. Gerbens-Leenes PW, Mekonnen MM \& Hoekstra AY (2013) The water footprint of poultry, pork and beef: a comparative study in different countries and production systems. Water Resour Ind 1, 25-36.

83. Heller MC, Willits-Smith A, Mahon T et al. (2021) Individual US diets show wide variation in water scarcity footprints. Nat Food 2, 255-263.

84. Machovina B, Feeley KJ \& Ripple WJ (2015) Biodiversity conservation: the key is reducing meat consumption. Sci Total Environ 536, 419-431.

85. Williams DR, Clark M, Buchanan GM et al. (2021) Proactive conservation to prevent habitat losses to agricultural expansion. Nat Sustain 4, 314-322.

86. Henders S, Persson UM \& Kastner T (2015) Trading forests: land-use change and carbon emissions embodied in production and exports of forest-risk commodities. Environ Res Lett 10, 125012.

87. Steinfeld H, Gerber P, Wassenaar T et al. (2006) Livestock's Long Shadow: Environmental Issues and Options. Rome, Italy: Food \& Agriculture Organization. 